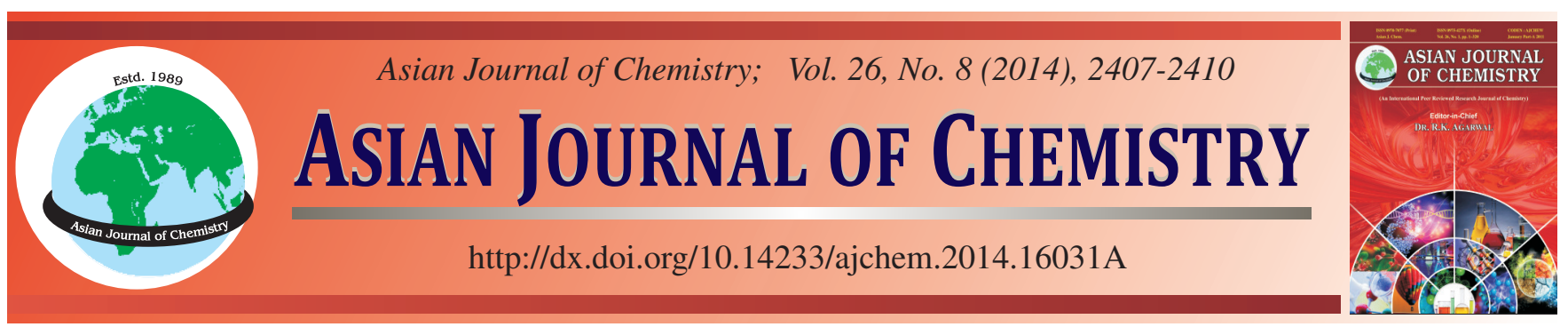

\title{
Influence of Modification Amount, Reactant Concentration and pH Value on the Photocatalytic Activity of Ionic Liquid Modified $\mathrm{TiO}_{2}$ Under Visible Light
}

\author{
S.Z. Hu ${ }^{*}$, F.Y. Li and Z.P. FAN
}

Institute of Eco-environmental Sciences, Liaoning Shihua University, Fushun 113001, P.R. China

*Corresponding author: Tel: +86 24 23847473; E-mail: hushaozheng001@163.com

Ionic liquid $\left([\mathrm{Bmim}] \mathrm{OH},[\mathrm{Bmim}] \mathrm{Br},[\mathrm{Bmim}] \mathrm{BF}_{4}\right)$ modified $\mathrm{TiO}_{2}$ catalysts were prepared by hydrothrmal method. XRD and UV-visible spectra were used to characterize the prepared composite materials. Ionic liquid modification did not change the crystalline structure of $\mathrm{TiO}_{2}$ particles but reduced the particle size. [Bmim] $\mathrm{OH}$ modified $\mathrm{TiO}_{2}$ shows the obviously enhanced visible light absorption. The influence of ionic liquid types, modification amount, reactant concentration and $\mathrm{pH}$ value on the photocatalytic activity of $\mathrm{TiO}_{2}$ catalyst under visible light were investigated.

Keywords: Ionic liquid, $\mathrm{TiO}_{2}$, Modification, Photocatalyst, Visible light.

\section{INTRODUCTION}

Photocatalytic technology has attracted worldwide research interest for the degradation of toxic pollutants in water, air and soil. Among the various photocatalysts, $\mathrm{TiO}_{2}$ has proven to be the promising one because of its features such as nontoxicity, high efficiency, chemical stability, low cost and environmentally friendly. It has wide applications including mineralization of toxic organic substances, water splitting and solar cell ${ }^{1,2}$. However, the wide band gap of titania photocatalyst makes it only active under UV irradiation. Therefore, the photocatalytic activity of $\mathrm{TiO}_{2}$ need to be further improved for the practical applications ${ }^{3,4}$. In order to the efficient utilization of solar energy, it is still a big challenge to develop $\mathrm{TiO}_{2}$ photocatalysts with highly activity under visible light.

It is reported that $\mathrm{TiO}_{2}$ doped with transition metals could absorb visible light and exhibited high photocatalytic activity under visible light irradiation ${ }^{5,6}$. However, the disadvantage of metal cation dopants is that they can serve as recombination centers for photogenerated electron-hole pairs, leading to a decreased activity ${ }^{7}$. Recently, the substitution of non-metal atoms, such as nitrogen ${ }^{8}$, sulfur ${ }^{9}$, phosphorous $^{10}$, iodine $^{11}$, and boron ${ }^{12}$, for oxygen in the lattice of $\mathrm{TiO}_{2}$ was reported to enhance the catalytic activity of $\mathrm{TiO}_{2}$ under visible light. But the synthesis of the nonmetal-doped $\mathrm{TiO}_{2}$ materials is much more difficult, because the lattice exchange requires high temperature and complicated procedures. Recently, much interest has been focused on the surface modification of $\mathrm{TiO}_{2}$ with organic dyes for the construction of dye-sensitized photocatalytic systems under visible light irradiation ${ }^{13}$. Since the dye molecules are generally absorbed on rather than chemically bonded to the surface of $\mathrm{TiO}_{2}$, resulting in a gradual decrease in photocatalytic activity.

Ionic liquids (ILs) are low melting salts with negligible vapour pressure and represent a new and promising solvent class, particularly with regard to homogeneous two phase catalysis and extractions. The high potential of ionic liquids will probably lead to an increasing demand. The combination of ionic liquids with nanotechnology has led to some major advances in materials science. Nanorods, nanospheres, nanotubes, mesostructures of $\mathrm{TiO}_{2}$ phases have been synthesized using ionic liquid as the solvent, electrolyte and template ${ }^{14-17}$. However, little effort has been devoted to the study of the photocatalytic performances of the ionic liquid-modified $\mathrm{TiO}_{2}$ materials under visible light. Here, different kind of ionic liquids modified $\mathrm{TiO}_{2}$ nanocomposites were synthesized via a hydrothermal procedure. The influence of [Bmim] $\mathrm{OH}$ amount, $\mathrm{pH}$ value, reactant concentration and ionic liquid types on the photocatalytic performane under visible light were investigated.

\section{EXPERIMENTAL}

Titanium(IV) chloride $(0.8 \mathrm{~mL})$ was added dropwise into $10 \mathrm{~mL}$ ethanol to form solution $\mathrm{A}$. A desired amount of ionic liquid $\left([\mathrm{Bmim}] \mathrm{OH},[\mathrm{Bmim}] \mathrm{Br},[\mathrm{Bmim}] \mathrm{BF}_{4}\right)$ was added into another $10 \mathrm{~mL}$ ethanol to form solution $\mathrm{B}$. These two solutions were mixed under stirring to form a clear solution. Ammonia 
was then added dropwise into the solution and $\mathrm{TiO}_{2}$ precipitates were formed. More ammonia was added dropwise until the $\mathrm{pH}$ of the mixture reached ${ }^{8}$. The formed suspension was stirred for $0.5 \mathrm{~h}$ and then transferred into a $30 \mathrm{~mL}$ stainless steel autoclave, which was then heated to $160{ }^{\circ} \mathrm{C}$ and kept for $24 \mathrm{~h}$. The solid product was separated by filtration, followed by washing and drying at $80{ }^{\circ} \mathrm{C}$ for $8 \mathrm{~h}$. The obtained orange sample was denoted as $\mathrm{OH}-\mathrm{TiO}_{2}(\mathrm{x}), \mathrm{Br}^{-\mathrm{TiO}_{2}}(\mathrm{x})$ and $\mathrm{BF}_{4}$ $\mathrm{TiO}_{2}(\mathrm{x})$, where $\mathrm{x}$ stands for the molar ratio of ionic liquid to $\mathrm{TiCl}_{4}$. For comparison, neat $\mathrm{TiO}_{2}$ was prepared by the same procedure described above but in the absence of ionic liquid.

XRD patterns of the prepared $\mathrm{TiO}_{2}$ nanocomposites were recorded on a Rigaku D/max-2400 instrument using $\mathrm{Cu}-\mathrm{K}_{\alpha}$ radiation $(1=1.54 \AA$ ). The zeta-potential of the catalyst was measured at room temperature on Zetasizer Nano S90 (Malvern Instruments). The $\mathrm{pH}$ was adjusted by dropwise addition of dilute $\mathrm{HCl}$ or $\mathrm{NaOH}$ solution. UV-visible spectroscopy measurement was carried out on a Jasco V-550 spectrophotometer, using $\mathrm{BaSO}_{4}$ as the reference.

Photocatalytic reaction: Methylene blue (MB) was selected as model compound to evaluate the photocatalytic performance of the prepared $\mathrm{TiO}_{2}$ particles in an aqueous solution under visible light irradiation. $0.1 \mathrm{~g} \mathrm{TiO}_{2}$ powders were dispersed in $100 \mathrm{~mL}$ aqueous solution of methylene blue (50 ppm) in an ultrasound generator for $10 \mathrm{~min}$. The suspension was transferred into a self-designed glass reactor and stirred for $0.5 \mathrm{~h}$ in darkness to achieve the adsorption equilibrium. In the photoreaction under visible light irradiation, the suspension was exposed to a 110-W high-pressure sodium lamp with main emission in the range of 400-800 $\mathrm{nm}$ and air was bubbled at $130 \mathrm{~mL} / \mathrm{min}$ through the solution. The UV light portion of sodium lamp was filtered by $0.5 \mathrm{M} \mathrm{NaNO}_{2}$ solution. All runs were conducted at ambient pressure at $30{ }^{\circ} \mathrm{C}$. At given time intervals, $4 \mathrm{~mL}$ suspension was taken and immediately centrifuged to separate the liquid samples from the solid catalyst. The concentrations of methylene blue before and after reaction were measured by means of a UV-visible spectrophotometer at a wavelength of $665 \mathrm{~nm}$. It is the linear relationship between absorbance and concentration of liquid sample in the experimental concentration range. Therefore, the percentage of degradation $\mathrm{D} \%$ was determined by the absorbances of the liquid sample before and after degradation.

\section{RESULTS AND DISCUSSION}

Fig. 1 shows the XRD patterns of the synthesized $\mathrm{TiO}_{2}$ nanocomposites. There are three phases, rutile, brookite and anatase, in $\mathrm{TiO}_{2}$. Pure anatase $\mathrm{TiO}_{2}$ with characteristic diffractions at $25.2^{\circ}\left(\begin{array}{lll}1 & 0 & 1\end{array}\right), 37.8^{\circ}\left(\begin{array}{lll}0 & 0 & 4\end{array}\right), 48.1^{\circ}\left(\begin{array}{lll}2 & 0 & 0\end{array}\right), 54.7^{\circ}\left(\begin{array}{lll}1 & 0 & 5\end{array}\right)$ and $62.7^{\circ}(211)$ was shown in all $\mathrm{TiO}_{2}$ samples. The modification of $\mathrm{TiO}_{2}$ by ionic liquids did not cause any change in peak positions in XRD pattern. However, the peak intensity was slightly decreased whereas the full width at half-maximum (FWHM) increased on increasing the concentration of ionic liquids. It is therefore suggested that ionic liquids modification did not change the crystalline structure of $\mathrm{TiO}_{2}$ particles but reduced the particle size. The calculation by Debye-Scherrer equation revealed that the average particle sizes of neat $\mathrm{TiO}_{2}$, OH-TiO $2(3), \mathrm{Br}_{-} \mathrm{TiO}_{2}(3)$ and $\mathrm{BF}_{4}-\mathrm{TiO}_{2}(3)$ were $10.3,8.5,8.9$ and $9.1 \mathrm{~nm}$, respectively. When different amount of $[\mathrm{Bmim}] \mathrm{OH}$ was used to modify $\mathrm{TiO}_{2}$ sample, the XRD result (not shown here) indicated that the crystalline structure of $\mathrm{TiO}_{2}$ particles also did not changed and the particle size reduced with increasing the $[\mathrm{Bmim}] \mathrm{OH}$ amount.

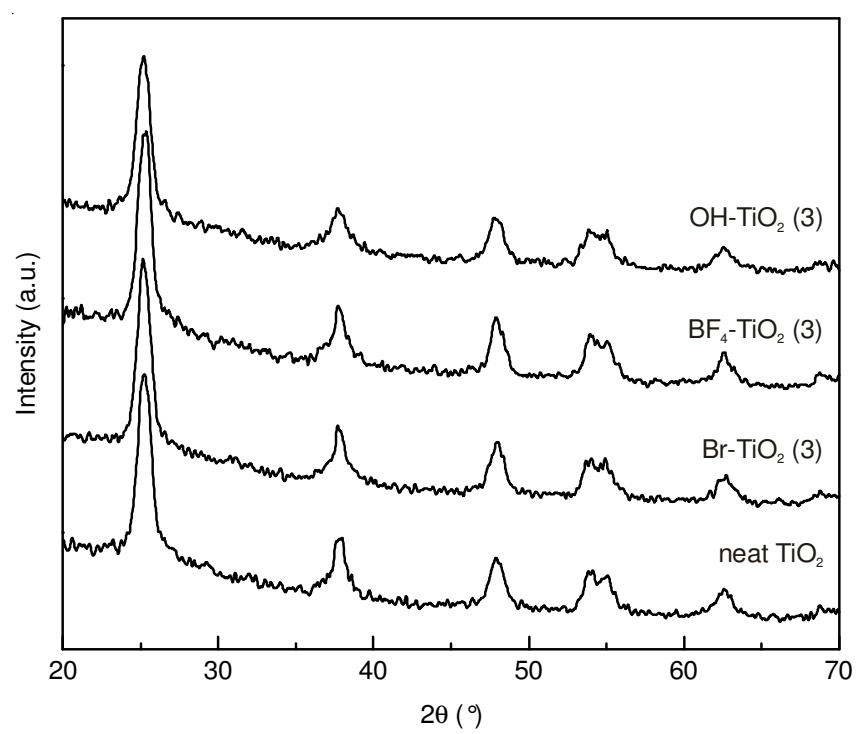

Fig. 1. XRD patterns of prepared $\mathrm{TiO}_{2}$ samples

In Fig. 2, UV-visible spectra of prepared catalysts, no absorption in visible light region for neat $\mathrm{TiO}_{2}$ was observed. After $[\mathrm{Bmim}] \mathrm{Br}$ and $[\mathrm{Bmim}] \mathrm{BF}_{4}$ modification, a slight increased absorption in visible light region were observed for $\mathrm{Br}-\mathrm{TiO}_{2}(3)$ and $\mathrm{BF}_{4}-\mathrm{TiO}_{2}(3)$. However, after $[\mathrm{Bmim}] \mathrm{OH}$ modification, the obvious increased absorption was shown in visible light region, indicating [Bmim] $\mathrm{OH}$ modification could extend the absorption ability to visible light region. This increased absorption coud be due to the electrons transfer between $\mathrm{TiO}_{2}$ and [Bmim $] \mathrm{OH}$. Such absorption is significant for its application under visible light.

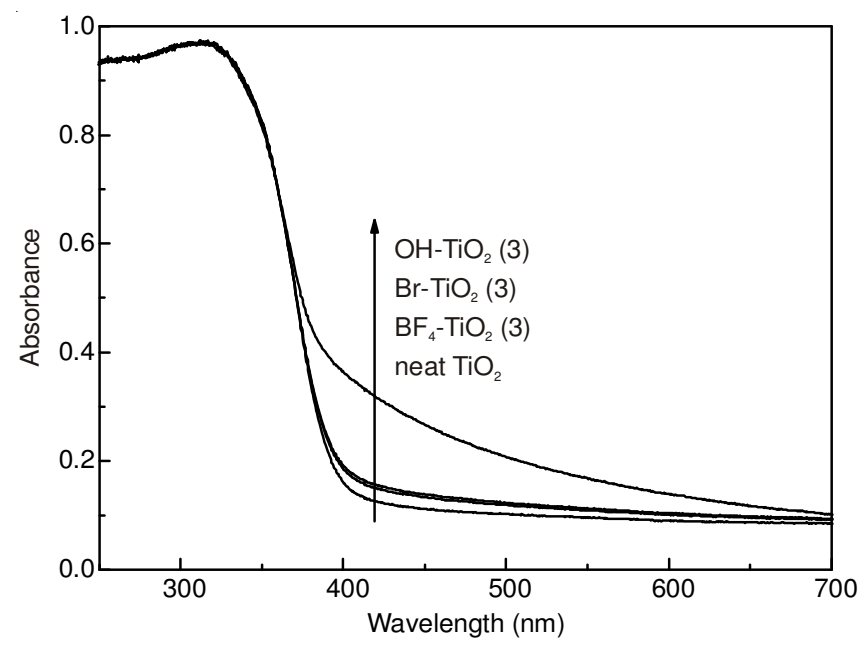

Fig. 2. UV-visible diffuse reflectance spectra of prepared $\mathrm{TiO}_{2}$ samples

Fig. 3 shows the photocatalytic activities of ionic liquids modified $\mathrm{TiO}_{2}$ catalysts under visible light. Neat $\mathrm{TiO}_{2}$ shows almost no activity under visible light. After [Bmim]Br and $[\mathrm{Bmim}] \mathrm{BF}_{4}$ modification, slight increase in activities were 
observed. However, for [Bmim] $\mathrm{OH}$ modified $\mathrm{TiO}_{2}$, obviously increase in activity was shown, over $80 \%$ methylene blue was degraded. This result is consistent with the UV-visible result that $[\mathrm{Bmim}] \mathrm{Br}$ and $[\mathrm{Bmim}] \mathrm{BF}_{4}$ modification only slight increase the visible light absorption whereas [Bmim] OH modified $\mathrm{TiO}_{2}$ exhibit obvious increase absorption. It has been reported that the Ti-OH can react with phenolic hydroxyl of organic compounds, such as catechol ${ }^{18}$, salicylic acid ${ }^{19}$ and binaphthol ${ }^{20}$, to form Ti-O-C bond on $\mathrm{TiO}_{2}$ surface. Therefore, this is probably due to that the surface of $\mathrm{TiO}_{2}$ particles is supposed to be positively charged, so Ti-OH may react with [Bmim] $\mathrm{OH}$ to form a Ti-O-C bond by elimination of a molecular $\mathrm{H}_{2} \mathrm{O}$. For other two ionic liquids, such reaction can not occurred.

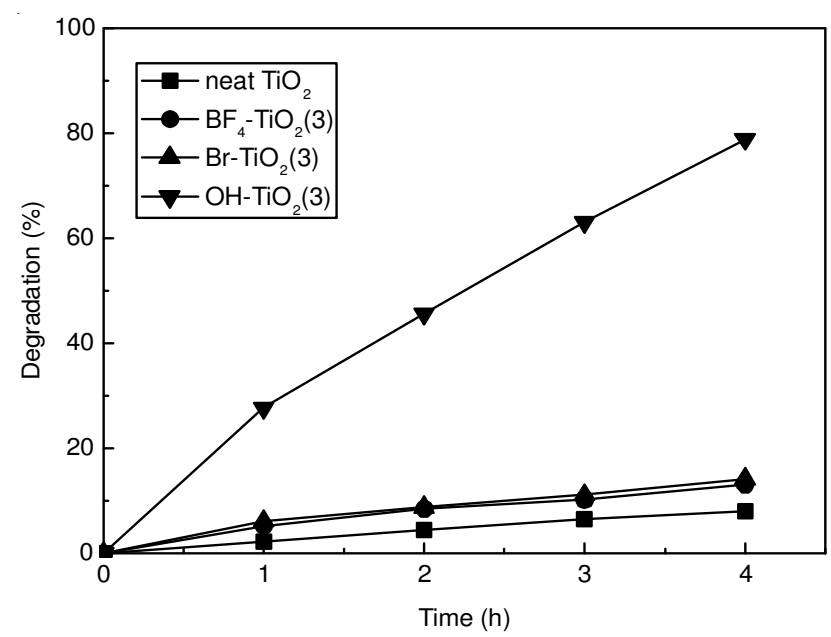

Fig. 3. Photocatalytic performance of ionic liquids modified $\mathrm{TiO}_{2}$ catalysts

Fig. 4 shows the effect of modification amount of [BMIM] $\mathrm{OH}$ on photocatalytic performances of $\mathrm{OH}-\mathrm{TiO}_{2}(3)$ under visible light irradiation. Obviously, the activity increased with incrasing the [BMIM]OH modification amount firstly from molar ratio $1: 1$ to $1: 3$. Further increase the [BMIM]OH modification amount to molar ratio 1:4, the activity decreased. This may be attributed to the coverage of the $\mathrm{TiO}_{2}$ surface by excess $[\mathrm{Bmim}] \mathrm{OH}$, leading to a decreased adsorption of methylene blue. Therefore, the optimal molar ratio is $1: 3$.

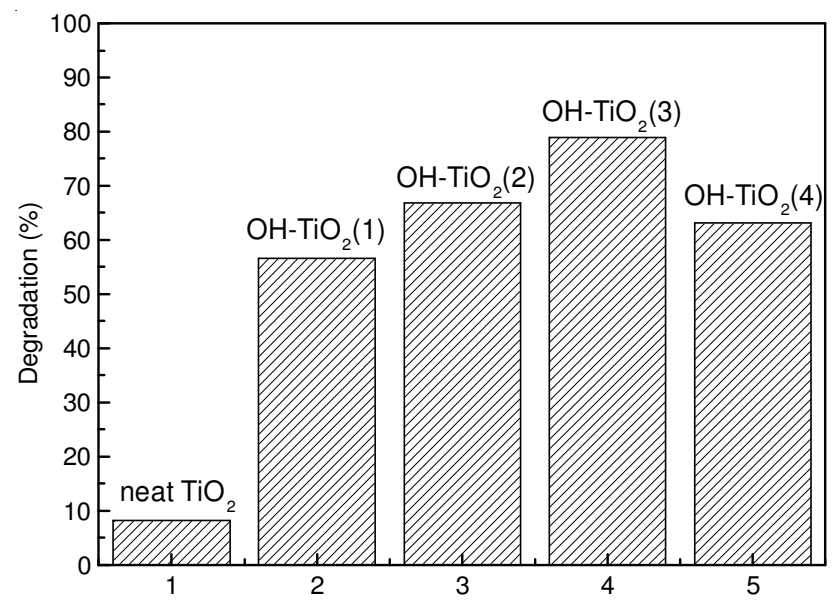

Fig. 4. Effect of modification amount of [BMIM]OH on photocatalytic performances of prepared $\mathrm{TiO}_{2}$ catalysts under visible light irradiation
Fig. 5 shows the effect of reactant concentration on photocatalytic performances of $\mathrm{OH}-\mathrm{TiO}_{2}(3)$ under visible light irradiation. For reactant concentration of $25 \mathrm{ppm}$, the degradation rate was over $60 \%$. Increasing the reactant concentration to $50 \mathrm{ppm}$, the degradation rate increase to $80 \%$. Further increase the reactant concentration to 75 and $100 \mathrm{ppm}$ lead to the obviously decreased activities. This is probably due to the excess methylene blue molecule can not be adsorbed on $\mathrm{TiO}_{2}$ simultaneously. Besides, the excess methylene blue concentration cause the light can not penetrate the solution and irradiate the $\mathrm{TiO}_{2}$ surface effectively. Thus, the optimal reactant concentration was $50 \mathrm{ppm}$.

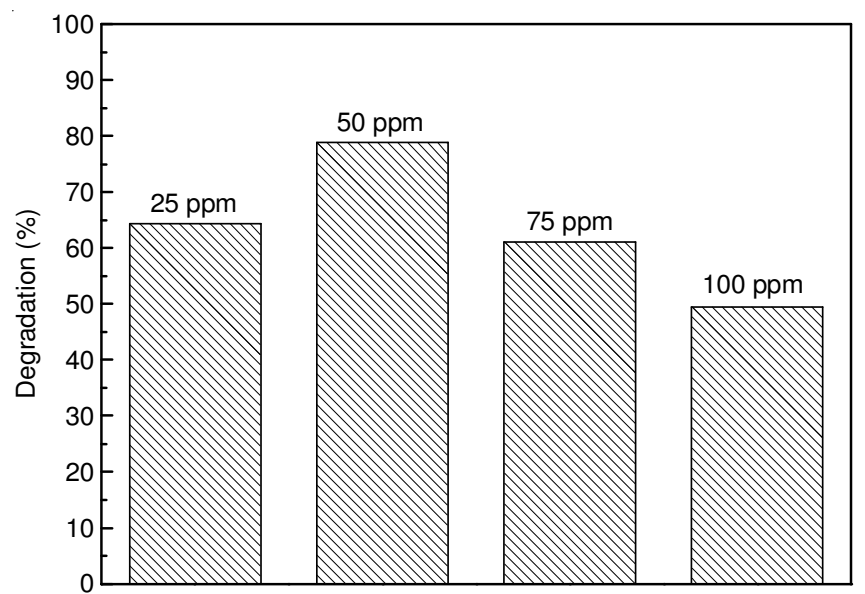

Fig. 5. Effect of reactant concentration on photocatalytic performances of $\mathrm{OH}-\mathrm{TiO}_{2}(3)$ under visible light irradiation

Fig. 6 shows the effect of $\mathrm{pH}$ value on photocatalytic performances of $\mathrm{OH}-\mathrm{TiO}_{2}(3)$ under visible light irradiation. It is shown that the solution with $\mathrm{pH}=7$ exhibit the highest photocatalytic activity. No matter acidic and basic system lead to the poor activity. It is concluded that the Ti-OH may react with $[\mathrm{Bmim}] \mathrm{OH}$ to form a Ti-O-C bond. Thus $[\mathrm{Bmim}] \mathrm{OH}$ could effective modify $\mathrm{TiO}_{2}$ whereas other two ionic liquid can not. Therefore, under acidic and basic system, this reaction will be restrained, thus leading to the decreased activity.

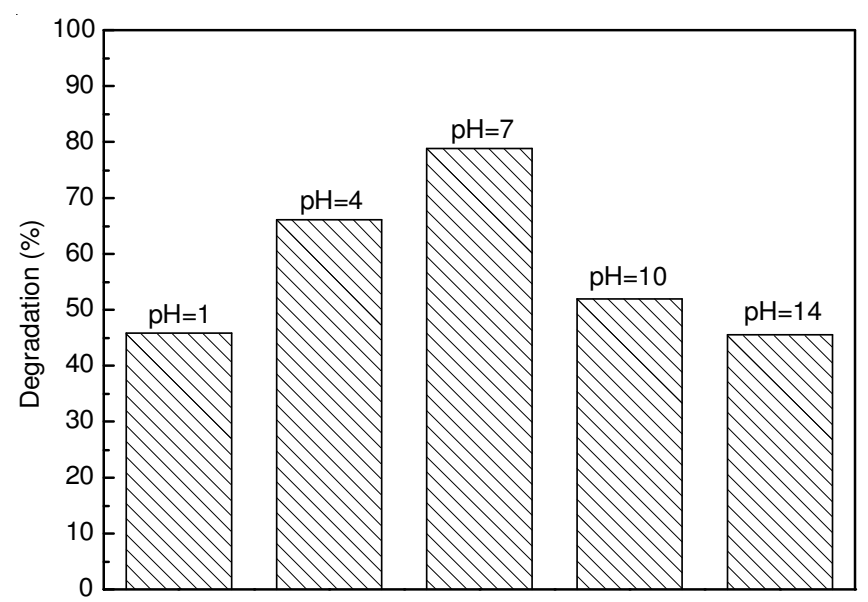

Fig. 6. Effect of pH value on photocatalytic performances of $\mathrm{OH}-\mathrm{TiO}_{2}(3)$ under visible light irradiation 


\section{Conclusion}

Ionic liquid ([Bmim] $\left.\mathrm{OH},[\mathrm{Bmim}] \mathrm{Br},[\mathrm{Bmim}] \mathrm{BF}_{4}\right)$ modified $\mathrm{TiO}_{2}$ catalysts were prepared by hydrothrmal method. Ionic liquid modification did not change the crystalline structure of $\mathrm{TiO}_{2}$ particles but reduced the particle size. [Bmim] OH modified $\mathrm{TiO}_{2}$ shows the obviously enhanced visible light absorption whereas other two ionic liquid can not. This is probably due to $\mathrm{Ti}-\mathrm{OH}$ react with $[\mathrm{Bmim}] \mathrm{OH}$ to form a Ti-O-C bond. Thus [Bmim] OH could modify $\mathrm{TiO}_{2}$ effectively. The optimal reaction condition was molar ratio of ionic liquid to $\mathrm{TiCl}_{4}$ of $3: 1$, methylene blue concentration of $50 \mathrm{ppm}, \mathrm{pH}$ value $=7$.

\section{ACKNOWLEDGEMENTS}

This work was supported by Program for New Century Excellent Talents in University (No. NCET-11-1011), National Natural Science Foundation of China (No. 41071317, 30972418, 21103077), National Key Technology R \& D Program of China (No. 2007BAC16B07, 2012ZX07505-001), the Natural Science Foundation of Liaoning Province (No. 20092080).

\section{REFERENCES}

1. A. Mills and S. LeHunte, J. Photochem. Photobiol. A, 108, 1 (1997).

2. A. Fujishima, T.N. Rao and D.A. Tryk, J. Photochem. Photobiol. C: Photochem. Rev., 1, 1 (2000).

3. H. Kominami, S. Murakami, J. Kato, Y. Kera and B. Ohtani, J. Phys. Chem. B., 106, 10501 (2002).
4. P.V. Kamat, Chem. Rev., 93, 267 (1993).

5. S. Klosek and D. Raftery, J. Phys. Chem. B, 105, 2815 (2001).

6. H. Yamashita, M. Harada, J. Misaka, M. Takeuchi, K. Ikeue and M. Anpo, J. Photochem. Photobiol. A, 148, 257 (2002).

7. W. Choi, A. Termin and M.R. Hoffmann, J. Phys. Chem., 98, 13669 (1994).

8. Y.N. Huo, Z.F. Bian, X.Y. Zhang, Y. Jin, J. Zhu and H.X. Li, J. Phys. Chem. C., 112, 6546 (2008).

9. H.J. Sun, H.L. Liu, J. Ma, X.Y. Wang, B. Wang and L. Han, J. Hazard. Mater., 156, 552 (2008).

10. Q. Shi, D. Yang, Z.Y. Jiang and J. Li, J. Mol. Catal. B, 43, 44 (2006).

11. R. Abe, K. Sayama, K. Domen and H. Arakawa, Chem. Phys. Lett., 344, 339 (2001).

12. A. Zaleska, J.W. Sobczak, E. Grabowska and J. Hupka, Appl. Catal. B, 78, 92 (2008).

13. D. Chatterjee and A. Mahata, Appl. Catal. B, 33, 119 (2001).

14. I. Paramasivam, J.M. Macak, T. Selvam and P. Schmuki, Electrochim. Acta., 54, 643 (2008).

15. K.S. Yoo, T.G. Lee and J. Kim, Micropor. Mesopor. Mater., 84, 211 (2005).

16. K.L. Ding, Z.J. Miao, Z.M. Liu, Z.F. Zhang, B.X. Han, G.M. An, S.D. Miao and Y. Xie, J. Am. Chem. Soc., 129, 6362 (2007).

17. Y. Liu, J. Li, M.J. Wang, Z.Y. Li, H.T. Liu, P. He, X.R. Yang, J.H. Li, Cryst. Growth Des., 5, 1643 (2005).

18. Y. Liu, J.I. Dadap, D. Zimdars and K.B. Eisenthal, J. Phys. Chem. B., 103, 2480 (1999).

19. A.E. Regazzoni, P. Mandelbaum, M. Matsuyoshi, S. Schiller, S.A. Bilmes and M.A. Blesa, Langmuir, 14, 868 (1998).

20. S. Ikeda, C. Abe, T. Torimoto, B. Ohtani, J. Photochem. Photobiol. A: Chem., 160, 61 (2003). 